\title{
TRATAMENTO DE DADOS PESSOAIS DOS CONSUMIDORES : UMA ANÁLISE CRÍTICA ACERCA DOS DIREITOS PREVISTOS NA LEI No 13.709/2018 E DA RESPONSABILIZAÇÃO DOS AGENTES PELA AUTORIDADE NACIONAL
} Joseane Suzart Lopes da Silva ${ }^{1}$

RESUMO: O problema desta pesquisa consiste em averiguar se a autoridade nacional destinada à proteção de dados pessoais terá condições de efetivamente assegurar a prevenção e o combate às práticas deletérias prejudiciais aos dados pessoais dos consumidores. A hipótese central concerne em verificar se os dispositivos legais viabilizam a tutela dos interesses e direitos dos consumidores, ou se urge uma necessária integração com o Sistema Nacional de Proteção e Defesa do Consumidor (SNDC) em harmonização com os postulados do microssistema específico instituído pela Lei Federal n. 8.078/90. Foram utilizados os métodos hermenêutico, dialético e argumentativo, bem como a pesquisa exploratória, bibliográfica e documental . PALAVRAS-CHAVE: DADOS PESSOAIS - CONSUMIDORES -DIREITOS RESPONSABILIDADE - AUTORIDADE NACIONAL.

THE PROTECTION OF PERSONAL DATA OF CONSUMERS AND LAW N. 13709/2018: IN SEARCH OF THE EFFECTIVENESS OF THE RIGHTS TO PRIVACY, INTIMIDITY AND SELF-DETERMINATION

ABSTRACT: The problem of this research is to investigate whether Federal Law $13709 / 2018$, which deals with the processing of personal data, will contribute to the effective protection of consumers. The central hypothesis concerns the verification of which legal devices, conform to the established by Federal Law n. 8.078 / 90, and those that give rise to a critical interpretation and careful application by the National System of Consumer Protection and Defense (SNDC) in harmony with the postulates of the specific microsystem. The hermeneutic, dialectical and argumentative methods were used, following the critical-methodological section, as well as the exploratory, bibliographic and documentary research.

KEYWORDS: PERSONAL DATA - CONSUMERS - PRIVACY - INTIMACY SELF-DETERMINATION.

\section{INTRODUÇÃO}

Em 14 de agosto de 2018, foi editada a Lei Federal no 13.709, que dispõe sobre a proteção de dados pessoais e, em seguida, a Medida Provisória $n^{\circ}$ 869/2018 versou sobre a instituição da autoridade nacional sobre a temática. As informações que caracterizam certo indivíduo, para que possam ser conhecidas e manejadas, devem passar pelo crivo do aval deste, mas, no nosso País, evidencia-se, com uma constância

\footnotetext{
${ }^{1}$ Promotora de Justiça do Consumidor do MPBA. Professora Adjunta FDUFBA. Coordenadora Científica do Projeto de Extensão ABDECON/FDUFBA e Diretora BRASILCON para a Região Nordeste.
} 


\section{TRATAMENTO DE DADOS PESSOAIS DOS CONSUMIDORES \\ : UMA ANÁLISE CRÍTICA ACERCA DOS DIREITOS \\ PREVISTOS NA LEI No 13.709/2018 E DA \\ RESPONSABILIZAÇÃO DOS AGENTES PELA AUTORIDADE \\ NACIONAL}

preocupante, incidentes que denotam a violação ao direito fundamental dos destinatários finais de produtos e/ou serviços, previsto na Constituição Federal de 1988 e na Lei Federal n. 8.078/90, que instituiu o microssistema consumerista.

O problema científico da presente pesquisa consiste em averiguar se a autoridade nacional destinada à proteção de dados pessoais terá condições de efetivamente assegurar a prevenção e o combate às práticas deletérias prejudiciais aos dados pessoais dos consumidores. Objetiva-se, assim, examinar se o novel arcabouço jurídico propiciará a promoção e a defesa dos direitos fundamentais de liberdade, privacidade e de desenvolvimento da personalidade dos indivíduos adquirentes e/ou utentes de bens. A hipótese central arregimentada concerne em verificar se os dispositivos legais, que integram o aludido prospecto normativo, viabilizam a tutela dos interesses e direitos dos consumidores, ou se urge uma necessária integração com o Sistema Nacional de Proteção e Defesa do Consumidor (SNDC) em harmonização com os postulados do microssistema específico instituído pela Lei Federal n. 8.078/90.

Nessa senda, destina-se este artigo a abordar as principais inovações constantes na dita estrutura legislativa, perpassando, inicialmente, pelos conceitos básicos para se compreender o campo de sua incidência. Transpõe-se, após, a análise para a sistemática de tratamento de dados pessoais, ressaltando-se os direitos dos titulares. Por fim, serão examinadas as normas que versam sobre a responsabilidade dos agentes que lidam com o tratamento de dados pessoais e a atuação da autoridade nacional. Para a realização deste empreendimento, optou-se pelos métodos hermenêutico, dialético e argumentativo, seguindo-se a vertente crítico-metodológica e as linhas de investigação jurídico-projetiva e jurídico-prospectiva. O tipo de pesquisa concretizada foi a exploratória, de natureza bibliográfica e documental, bem como a técnica da documentação indireta (HERRERA, 1998; WITKER, 1985; BECKER, 1999).

\section{A LEI N. 13.709/2018: CONCEITOS FUNDAMENTAIS E ÂMBITO DE}




\section{TRATAMENTO DE DADOS PESSOAIS DOS CONSUMIDORES \\ : UMA ANÁLISE CRÍTICA ACERCA DOS DIREITOS \\ PREVISTOS NA LEI No 13.709/2018 E DA \\ RESPONSABILIZAÇÃO DOS AGENTES PELA AUTORIDADE \\ NACIONAL}

\section{INCIDÊNCIA.}

Os dados pessoais dos consumidores, na conjuntura atual, são muito valiosos para o mercado de fornecimento de produtos e/ou serviços, razão pela qual afirma-se que se vive na "sociedade informacional" ou "da informação". A despeito de tais expressões parecerem sinônimas, Manuel Castells apresenta uma distinção conceitual, visto que, para ele, a primeira indica uma forma específica de agrupamento, na qual a geração, o processamento e a transmissão da informação "tornam-se fontes fundamentais de produtividade" devido às novas condições tecnológicas oriundas do período histórico vivenciado (CASTELLS, 2008, p. 64-65). Vigora, segundo MayerSchöemberger, o "paradigma da memória" e, no campo mercadológico, tenciona-se armazenar e utilizar os dados dos consumidores para lhes impingir publicidades específicas e os estimular a adquirir bens (MAYER-SCHÖEMBERGER, 2009, p. 78).

A compreensão das atuais normas que arregimentam o tratamento de dados pessoais no Brasil pressupõe a prévia análise de conceitos essenciais que delimitam o seu âmbito de aplicação. Sobre o conceito de dados pessoais, afirma Catarina Sarmento e Castro, que estes "compreendem qualquer informação alfabética, gráfica, fotográfica, acústica, independente do suporte (som e imagem), referente a pessoa identificada ou identificável” (CASTRO, 2005, p. 70-88). Para Pierre Catala, considerado pioneiro na abordagem sistemática da teoria jurídica da informação, poderá ser classificada em quatro modalidades: (i) as relativas às pessoas e seus patrimônios; (ii) as opiniões subjetivas das pessoas; (iii) as obras do espírito; e finalmente (iv) as que, fora das modalidades anteriores, referem-se a "descrições de fenômenos, coisas, eventos (CATALA, 1983, p. 22).

Seguindo-se o quanto preconizado pelo art. $2^{\circ}$ da Diretiva Europeia 95/46/CE, segundo o qual dados pessoais correspondem a "qualquer informação relativa a uma pessoa singular identificada ou identificável”, a Lei ${ }^{0}$ 13.709/2018 restringiu a sua incidência apenas para a proteção das pessoas naturais. Conforme disposto pelo art. $5^{\circ}$, inciso I, estas podem ser identificadas ou identificáveis, não abarcando o conjunto 


\section{TRATAMENTO DE DADOS PESSOAIS DOS CONSUMIDORES \\ : UMA ANÁLISE CRÍTICA ACERCA DOS DIREITOS \\ PREVISTOS NA LEI No 13.709/2018 E DA \\ RESPONSABILIZAÇÃO DOS AGENTES PELA AUTORIDADE \\ NACIONAL}

normativo aspectos atinentes às pessoas jurídicas (Cf.: BRIN, 1998; WACKS, 1989). Nessa senda, não serão aplicados os ditames daquele diploma legal aos itens anomizados.

De acordo com o art. $5^{\circ}$, inciso II, da Lei ${ }^{0} 13.709 / 18$, dado pessoal sensível é aquele vinculado à pessoa natural e que versa sobre origem racial ou étnica, convicção religiosa, opinião política, filiação a sindicato ou a organização de caráter religioso, filosófico ou político, saúde, vida sexual, genética ou biometria. De La Cueva alerta sobre a importância de tais informações, eis que se encontram vinculadas ao cerne essencial da personalidade e dignidade humanas; o que os torna "objeto de garantía sustantiva a través de outros derechos fundamentales" (DE LA CUEVA, 1993, p. 6970). Por serem informações de inquestionável importância, não podem ser submetidas a atividades arbitrárias por parte dos agentes controladores. Adriano De Cupis as denominou de "direitos essenciais" (DE CUPIS, 1982, p. 13), enquanto Paulo Mota Pinto as intitulou de "um círculo de direitos mínimos" (PINTO, 2017, p. 78).

Em decorrência das diversas peculiaridades derivadas de fatores, principalmente os oriundos da busca de exploração econômica, segundo De Cupis, tornou-se fundamental o desenvolvimento de meios de tutela específicos para os dados pessoais, mormente os sensíveis. Existem certos direitos, verbera o autor, sem os quais "a personalidade restaria uma susceptibilidade completamente irrealizada, privada de todo o valor concreto"; sem eles, todos os outros "perderiam todo o interesse para o indivíduo - o que equivale a dizer que, se eles não existissem, a pessoa não existiria como tal". São os intitulados "direitos essenciais, com os quais se identificam precisamente os direitos da personalidade" (DE CUPIS, 1982, p. 13).

A definição do que consiste o tratamento de dados encontra-se expressa, consistindo em toda operação realizada com informações pessoais, podendo ser por meio físico ou digital, englobando não somente a recepção, o acesso e a coleta, mas também atividades outras complementares. Poderá ocorrer apenas o armazenamento ou arquivamento, bem como o processamento, controle, avaliação e classificação de 


\section{TRATAMENTO DE DADOS PESSOAIS DOS CONSUMIDORES \\ : UMA ANÁLISE CRÍTICA ACERCA DOS DIREITOS \\ PREVISTOS NA LEI No 13.709/2018 E DA \\ RESPONSABILIZAÇÃO DOS AGENTES PELA AUTORIDADE \\ NACIONAL}

informações. Nessa senda, será possível a modificação, havendo alterações mediante a extração de partes ou o acréscimo (produção) ou mesmo a eliminação, e ainda a utilização, reprodução, comunicação, transmissão, distribuição, transferência e difusão (MESSINETTI, 1998, p. 339-407).

\section{O CONSENTIMENTO DO TITULAR DOS DADOS PESSOAIS PARA O TRATAMENTO.}

O consentimento do titular dos dados pessoais é primordial para o início do tratamento, sendo dispensado apenas nas hipóteses dispostas no art. $7^{\circ}$, incisos II a X, da Lei $n^{0} 13.709 / 2018$. Antes de qualquer ato vinculado à atividade, o controlador deverá observar se há manifestação livre, informada e inequívoca, pela qual o titular concorda com o procedimento que se refere às informações sobre a sua pessoa, para determinada finalidade explicitada. É o que dispõe o inciso XII do art. $5^{\circ}$ do referido diploma legal. Quanto à forma, o art. 14 estabelece que deverá ser fornecido por escrito ou por outro meio que demonstre a manifestação de vontade do titular, dando-se ensejo à comprovação pelos meios eletrônicos avançados. Como a dita regra permite outras modalidades de comprovação da concordância do interessado, premente será que os órgãos e entes que integram o Sistema Nacional de Proteção e Defesa do Consumidor (SNDC) atentem para a averiguação da veracidade do aval dos destinatários finais de produtos e/ou serviços (Cf.: ALMEIDA, 1982).

$\mathrm{O}$ parágrafo $1^{\mathrm{o}}$ daquele mesmo artigo dispõe que caso o consentimento seja fornecido por escrito, "esse deverá constar de cláusula destacada das demais cláusulas contratuais". Esta permissão é assaz preocupante, eis que, em várias oportunidades, as pessoas não atentam para o conteúdo dos contratos de adesão, elaborados, previamente, pelos fornecedores, principalmente, pelo fato de que, em regra, não conseguem sugerir alterações, conquanto o at. 54, parágrafo $1^{\circ}$ da Lei Federal $n^{\circ}$ 8.078/90, garanta-lhes este direito (Cf.: (BEAUCHARD, 1996; CALAIS-AULOY; STEINMETZ, 2006). Não se deve olvidar que, no Brasil, há uma quantidade elevada de pessoas estigmatizadas 


\section{TRATAMENTO DE DADOS PESSOAIS DOS CONSUMIDORES \\ : UMA ANÁLISE CRÍTICA ACERCA DOS DIREITOS \\ PREVISTOS NA LEI No 13.709/2018 E DA \\ RESPONSABILIZAÇÃO DOS AGENTES PELA AUTORIDADE \\ NACIONAL}

pelo analfabetismo funcional, pois conseguem assinar os seus nomes, mas sem a capacidade de verdadeira leitura e interpretação de textos e de redação (MARQUES; MIRAGEM, 2012, p. 45-60).

Os parágrafos $2^{\circ}$ a $4^{\circ}$ do art. $8^{\circ}$ estabelecem normas que visam resguardar os titulares dos dados pessoais, prevendo que compete ao controlador o ônus da prova de que a autorização foi obtida em conformidade com o quanto acima exposto, vedando-se vícios de consentimento e impondo que deverá referir-se a finalidades determinadas. São também consideradas nulas as autorizações genéricas para o tratamento de dados. Após, o parágrafo $5^{\circ}$ possibilita que o consentimento seja revogado, a qualquer momento, mediante manifestação expressa do titular, por procedimento gratuito e facilitado. No entanto, tais salvaguardas dependem da efetiva atuação da autoridade nacional que, lamentavelmente, teve a sua imediata instituição vetada pela Presidência da República.

A regra basilar para o tratamento de dados pessoais pressupõe o fornecimento de consentimento pelo titular, como disposto pelo art. $7^{\circ}$, inciso I, da Lei $n^{\circ}$ 13.709/18. Estabelece o parágrafo $5^{\circ}$, deste mesmo dispositivo, que o controlador, que obteve a permissão para lidar com as referidas informações, caso objetive comunicá-las ou realizar o seu compartilhamento com outros agentes, deverá providenciar confirmação específica. $\mathrm{O}$ uso em conjunto de dados pessoais poderá ocorrer entre entes ou órgãos públicos, no cumprimento de suas competências legais, assim como entre estes e entidades privadas, envolvendo a comunicação, difusão, transferência internacional e interconexão.

\subsection{DADOS PESSOAIS SENSÍVEIS E OS CONCERNENTES ÀS CRIANÇAS E ADOLESCENTES}

Para o tratamento de dados pessoais sensíveis, determina o art. 17 que o seu titular, ou responsável legal, consinta, de forma clara, consciente e destacada, para finalidades específicas (Cf.: ADER-DUCOS; AUBY, 1982). Poderá haver a atividade 


\section{TRATAMENTO DE DADOS PESSOAIS DOS CONSUMIDORES \\ : UMA ANÁLISE CRÍTICA ACERCA DOS DIREITOS \\ PREVISTOS NA LEI No 13.709/2018 E DA \\ RESPONSABILIZAÇÃO DOS AGENTES PELA AUTORIDADE \\ NACIONAL}

sem o prévio aval do interessado, nas hipóteses, acima examinadas, ou em prol da garantia de prevenção à fraude e em benefício da segurança daquele, nos processos de identificação e autenticação de cadastro em sistemas eletrônicos, excetuando-se os casos em que prevaleçam direitos e liberdades fundamentais que exijam a proteção dos dados pessoais. Em decorrência da peculiaridade e importância destas informações, será crucial um acompanhamento e fiscalização por parte da autoridade nacional, mas o veto às disposições que disciplinavam a atuação desta causa preocupação. Os entes que integram o Sistema Nacional de Defesa do Consumidor (SNDC) terão que realizar esta tarefa, mas já se encontram sobrecarregados com tantas outras funções e missões (BOURGOIGNIE, 1993, p. 7).

O tratamento de dados pessoais de crianças e de adolescentes deverá ser realizado em seu "melhor interesse", respeitando-se a legislação pertinente, sendo exigido o consentimento específico, em destaque, dado por, pelo menos, um dos pais ou pelo responsável legal. Exige o art. 20, parágrafo $2^{\circ}$, que os controladores mantenham, de forma pública, a informação sobre os tipos de itens coletados, o modo de sua utilização e os procedimentos para o exercício dos direitos. Poderão ser coletados dados pessoais de impúberes e jovens, sem o dito consentimento, quando forem necessários para contatar os pais ou o responsável legal, caso em que serão utilizados uma única vez e sem armazenamento, ou para protegê-las, não devendo ser repassados a terceiro sem autorização. Regra relevante encontra-se no parágrafo $4^{\circ}$, segundo a qual os controladores não deverão condicionar a participação dos titulares "em jogos, aplicações de internet ou outras atividades ao fornecimento de informações pessoais além das estritamente necessárias à atividade" (Cf. BARBER, 2009).

Tratando-se de dados sensíveis, dispõe o art. 11, parágrafo $3^{\circ}$, da Lei $\mathrm{n}^{\circ}$ 13.709/18, que, na hipótese de a comunicação, ou o uso compartilhado, tiver o objetivo de obter vantagem econômica, poderá "ser objeto de vedação ou de regulamentação por parte da autoridade nacional, ouvidos os órgãos setoriais do Poder Público, no âmbito de suas competências". O parágrafo $4^{\circ}$ coibiu tais atividades quando estiverem 


\section{TRATAMENTO DE DADOS PESSOAIS DOS CONSUMIDORES \\ : UMA ANÁLISE CRÍTICA ACERCA DOS DIREITOS \\ PREVISTOS NA LEI No 13.709/2018 E DA \\ RESPONSABILIZAÇÃO DOS AGENTES PELA AUTORIDADE \\ NACIONAL}

vinculadas à saúde com o objetivo de obter vantagem econômica, exceto nos casos de portabilidade de dados quando consentida pelo titular. Torna-se fundamental que haja a imprescindível e devida fiscalização dos agentes controladores com o fito de que não manuseiem tais informações peculiares de modo arbitrário (Cf.: RODOTÀ, 2008; RULE; HUNTER, 1999; MAYER-SCHÖEMBERGER, 2009).

\subsection{A DISPENSA DO CONSENTIMENTO DO TITULAR PARA O TRATAMENTO DE DADOS PESSOAIS}

Será dispensada a exigência do dito consentimento para "os dados tornados manifestamente públicos pelo titular, resguardados os direitos do titular e os princípios previstos”. Questiona-se o que qualificaria determinada informação como pública, deixando esta normativa ampla margem de interpretação e aplicação, sendo de extrema importância a regulamentação da matéria, a fim de se resguardar a situação dos consumidores que fazem uso das várias estruturas informatizadas para compartilhamento de notícias e múltiplas informações. Existem 03 (três) conjuntos de situações que podem ensejar a atividade independentemente da prévia aquiescência dos sujeitos interessados ou afetados, explanadas a seguir: 1) presença de bens jurídicos relevantes; 2) natureza da tarefa a ser executada; 3 ) cumprimento de obrigação legal ou regulatória.

Em toda e qualquer circunstância que englobar a tutela da vida, incolumidade física ou saúde do titular ou de terceiro, poderá haver o manejo de dados, por profissional encarregado da realização de procedimento ou entidade sanitária, mesmo que não se obtenha o prévio aval daquele. O mesmo sucede quando se tratar de proteção do crédito, não se devendo renegar a legislação consumerista já existente (Cf.: ALMEIDA, 1982; ALPA, 2001). No que concerne ao tipo de atividade empreendida, a execução de políticas públicas, previstas em leis e regulamentos ou respaldadas em contratos, convênios ou instrumentos congêneres, dispensa a obtenção de autorização dos beneficiários titulares de dados, mas estes devem ser comunicados. Situação 


\section{TRATAMENTO DE DADOS PESSOAIS DOS CONSUMIDORES : UMA ANÁLISE CRÍTICA ACERCA DOS DIREITOS \\ PREVISTOS NA LEI No 13.709/2018 E DA \\ RESPONSABILIZAÇÃO DOS AGENTES PELA AUTORIDADE NACIONAL}

idêntica observa-se quando se trata do exercício regular de direitos em processo judicial, administrativo ou arbitral, esse último nos termos da Lei $n^{\circ}$ 9.307/96. Na realização de estudos por órgão de pesquisa, também prescinde a concordância do titular, desde que garantida, sempre que possível, a anonimização dos dados pessoais. Quando o tratamento for necessário para a execução de contrato ou de procedimentos preliminares relacionados a tal instrumento, que tenham sido solicitados pelo próprio titular dos dados, é dispensada a busca de sua anterior aceitação, mas é preciso respeitar as normas consumeristas (CANCLINI, 2006; COMPARATO, 1976, p. 85-105).

Prescinde-se, igualmente, da outorga do titular para atender "aos interesses legítimos do controlador ou de terceiro", exceto "no caso de prevalecerem direitos e liberdades fundamentais do titular que exijam a proteção dos dados pessoais". O art. 16, nos incisos I e II, enumera algumas situações que podem caracterizá-los, mas não exclui outras. São considerados objetivos admissíveis o apoio e a promoção de atividades do controlador; e a proteção, em relação ao titular, do exercício regular de seus direitos ou prestação de serviços que o beneficiem, respeitadas as suas legítimas expectativas e os direitos e liberdades fundamentais (PÉREZ-LUÑO, 2005).

Tais normas acarretam uma ampla margem de liberdade para aqueles que detêm o monopólio da monitoria de informações pessoais, pressupondo uma atuação coesa e firme em prol da defesa dos direitos dos consumidores, uma vez que poderão ensejar uma série de manobras ilícitas que terminarão violando a proteção constitucional e legal que lhes foi concedida (Cf.: CANOTILHO, 2002). É crucial que haja uma regulamentação da matéria para se evitar que abusos sejam cometidos mediante o escudo de se atender às pretensões do setor mercadológico. $\mathrm{O}$ cumprimento de obrigação legal ou regulatória pelo controlador também dispensa autorização do titular, impondo o parágrafo $1^{\circ}$ do art. $7^{\circ}$ que, nessa hipótese, será informado. Contudo, não poderão ser sobrepujadas as normas que protegem os consumidores, não se sobrepondo estas aos ditames constantes na Lei Federal n. 8.078/90, como acentua Bruno Miragem (2017, p. 87-88). 


\section{TRATAMENTO DE DADOS PESSOAIS DOS CONSUMIDORES \\ : UMA ANÁLISE CRÍTICA ACERCA DOS DIREITOS \\ PREVISTOS NA LEI No 13.709/2018 E DA \\ RESPONSABILIZAÇÃO DOS AGENTES PELA AUTORIDADE \\ NACIONAL}

\section{DIREITOS ASSEGURADOS AO TITULAR DOS DADOS PESSOAIS EM FACE DO TRATAMENTO.}

Antes de se iniciar qualquer atividade referente a dados pessoais, devem os agentes zelar pela finalidade, adequação e necessidade do empreendimento que se pretende concretizar. A priori, é essencial observar que a realização do tratamento deve ter por esteio propósitos legítimos, específicos, explícitos e, previamente, informados ao titular, não sendo permitido qualquer desvirtuamento do que foi comunicado ao interessado, devendo amoldar-se a tais premissas (Cf.: ADER-DUCOS; AUBY, 1982). Há coibição de concretização do tratamento de dados para fins discriminatórios ilícitos ou abusivos, pois a adequação exige cumprimento ao direito à igualdade entre os indivíduos. Deverá haver ainda limitação do tratamento ao mínimo necessário para a realização de suas finalidades, com a utilização de dados pertinentes, proporcionais e não excessivos em relação às metas do tratamento (PARDOLESI, 2003, p. 55).

Os direitos dos titulares dos dados pessoais objeto de tratamento por agentes controladores podem ser examinados mediante a reunião em 05 (cinco) grupos, versando o primeiro sobre a confirmação da existência da atividade; o segundo concerne ao acesso ao conteúdo registrado; o terceiro diz respeito à obtenção de informações vinculadas ao assunto; o quarto açambarca a modificação ou exclusão das informações constantes nos arquivos; e o derradeiro refere-se à questão da portabilidade. $\mathrm{O}$ exercício daqueles direitos poderá ser efetivado a qualquer momento, mas pressupõe requerimento expresso do titular, ou de representante legalmente constituído perante o agente de tratamento, de acordo com o parágrafo $3^{\circ}$ do art. $8^{\circ}$ (Cf.: GONÇALVES, 1995). Consoante já verberado, em outros trechos do presente artigo, a criação da autoridade nacional será fundamental para a materialização do quanto assegurado, no plano legal, para os titulares dos direitos pessoais.

\subsection{A CONFIRMAÇÃO DO TRATAMENTO E O ACESSO AO CONTEÚDO REGISTRADO}




\section{TRATAMENTO DE DADOS PESSOAIS DOS CONSUMIDORES \\ : UMA ANÁLISE CRÍTICA ACERCA DOS DIREITOS \\ PREVISTOS NA LEI No 13.709/2018 E DA \\ RESPONSABILIZAÇÃO DOS AGENTES PELA AUTORIDADE NACIONAL}

Para a confirmação da ocorrência do tratamento de dados pessoais, o titular deverá apresentar requisição e, em seguida, atestando-se a sua realização, o interessado terá acesso ao conteúdo, podendo optar pelo meio eletrônico, seguro e idôneo para esse fim, ou pela forma impressa. Objetivando as informações de modo imediato, as receberá em formato simplificado; e caso opte pela obtenção de declaração mais completa, será fornecida no prazo de até 15 (quinze) dias, contados a partir da data do requerimento. Tal documento deverá ser redigido de forma clara e completa, indicando a origem dos dados, a inexistência de registro e os critérios utilizados para o tratamento, bem como a sua finalidade, observados os segredos comercial e industrial. $\mathrm{O}$ art. 43 , parágrafos $1^{\mathrm{o}} \mathrm{a}$ $5^{\circ}$, da Lei Federal $n^{\circ} 8.078 / 90$ contempla os direitos dos consumidores diante dos arquivos existentes e nota-se que o legislador delimitou, de modo mais específico, como pode portar-se os indivíduos perante qualquer empreendimento que lide com elementos caracterizadores dos seres humanos (Cf.: LEVY, 1998). Os dados pessoais deverão ser armazenados em formato que favoreça o exercício do direito de acesso por parte dos titulares, conforme determina o parágrafo $1^{\circ}$ do art. $9^{\circ}$ da Lei em análise. Tratando-se de crianças e adolescentes, as informações deverão ser fornecidas de maneira simples, clara e acessível, consideradas as características físico-motoras, perceptivas, sensoriais, intelectuais e mentais do usuário, mediante o uso de recursos audiovisuais, quando adequados (Cf.: FERRIER, 1996; GHERSI, 2004).

Garantiu-se, por meio do caput do art. $9^{\circ}$ da Lei, o direito do titular de acesso facilitado às informações sobre o tratamento de seus dados, devendo ser apresentadas, sem custos e de forma clara, adequada e ostensiva. Nos incisos I a VIII daquele mesmo dispositivo, foram listadas características obrigatórias que devem ser disponibilizadas para os interessados, além de outras, previstas em regulamentação, com o fito de que o princípio do livre acesso seja atendido de modo pleno. Consoante já externalizado em linhas precedentes, o titular dos dados possui o direito de ter conhecimento sobre a finalidade específica do tratamento, a sua forma e duração, observados os segredos comercial e industrial, bem como os direitos que lhes foram assegurados. Não se pode 


\section{TRATAMENTO DE DADOS PESSOAIS DOS CONSUMIDORES \\ : UMA ANÁLISE CRÍTICA ACERCA DOS DIREITOS \\ PREVISTOS NA LEI No 13.709/2018 E DA \\ RESPONSABILIZAÇÃO DOS AGENTES PELA AUTORIDADE \\ NACIONAL}

olvidar da proteção ao consumidor diante dos bancos de dados negativos e positivos, de acordo com o quanto disposto, respectivamente, pelas Leis Federais $n^{\text {os }} 8.078 / 90$ e 12.414/11 (Cf.: MAYER-SCHÖNBERGER, 2009; GONÇALVES, 2003).

Todo e qualquer cidadão poderá ter livre acesso aos seus dados pessoais, tendo sido garantida a consulta facilitada e gratuita sobre a forma e a duração do tratamento, bem como acerca da integralidade das informações. Assegurou-se, adrede, aos titulares a qualidade dos dados, caracterizada pela exatidão e clareza, assim como pela relevância e atualização, em consonância com a necessidade do seu manejo e o cumprimento da finalidade prevista e comunicada ao interessado (Cf.: OSSOLA; VALLESPINOS, 2001). Nessa senda, os sigilos decorrentes das atividades desenvolvidas não poderão sobrepujar a transparência das informações, que devem ser expressas, precisas e facilmente acessíveis.

Ademais, a identificação do controlador, como proceder o contato com este e as responsabilidades dos agentes devem ser explicitados. O compartilhamento de dados pelo controlador e a finalidade desta atividade devem ser também ser comunicados para os interessados. Em caso de impossibilidade de adoção imediata do quanto pleiteado pelo titular dos dados, compete ao controlador enviar-lhe resposta, comunicando-lhe que não é agente de tratamento, indicando, sempre que possível, o responsável. Sendo o realizador da atividade, mas não podendo adotar imediatamente as providências, também deverá informar ao interessado de modo justificado (Cf.: CASTRO, 2005; BENNETT, 1992)..

Quando o consentimento do titular for requerido, será considerado nulo caso as informações fornecidas denotem conteúdo enganoso ou abusivo ou não tenham sido apresentadas previamente com transparência, de forma clara e inequívoca. Havendo mudança da finalidade para o tratamento de dados pessoais, não compatível com a autorização original, o controlador deverá comunicar previamente ao titular, o qual poderá revogá-la, caso discorde das alterações. Nas hipóteses em que o tratamento de dados pessoais for condição para o fornecimento de produto ou de serviço ou para o

Rev. de Direito, Globalização e Responsabilidade nas Relações de Consumo| e-ISSN: 2526-0030| Goiânia| v. 5 | n. 1 | p. 82-104| Jan/Jun. 2019 


\section{TRATAMENTO DE DADOS PESSOAIS DOS CONSUMIDORES : UMA ANÁLISE CRÍTICA ACERCA DOS DIREITOS \\ PREVISTOS NA LEI No 13.709/2018 E DA \\ RESPONSABILIZAÇÃO DOS AGENTES PELA AUTORIDADE NACIONAL}

exercício de direito, o titular será informado, com destaque, sobre esse fato e acerca dos meios pelos quais poderá exercer os seus direitos (Cf. POULLET, 2009, p. 212). O fornecedor não poderá negar-se a disponibilizar bens para os consumidores de modo arbitrário com base em caracteres pessoais, visto que, dentre os pilares da estrutura normativa, sobressaem os direitos humanos, o livre desenvolvimento da personalidade, a dignidade e o exercício da cidadania, enunciados no inciso VII do art. $2^{\circ}$ da Lei $n^{\circ}$ 13.709/18. A despeito da preocupação do legislador com o resguardo das informações pertences aos indivíduos, prima-se também pelo desenvolvimento econômico e tecnológico e pela inovação, valorizando-se a livre iniciativa e a concorrência, jamais se desprezando a defesa do consumidor (Cf.: GHERSI, 2004; GHESTIN, 1962, p. 1-10).

\subsection{A MODIFICAÇÃO, A EXCLUSÃO, O BLOQUEIO E A} PORTABILIDADE DE DADOS PESSOAIS

O titular pode opor-se a tratamento realizado com fundamento em uma das hipóteses de dispensa de consentimento, em caso de descumprimento ao disposto no conjunto normativo em análise. Verificando-se alteração de informação referente à finalidade, forma e duração da atividade ou do uso compartilhado de dados, o controlador deverá informar o seu teor ao titular, de forma específica e destacada, podendo aquele revogar o seu aval, quando necessário, caso discorde da alteração. Quando a atividade tiver origem na aquiescência do titular ou em contrato, ele poderá solicitar cópia eletrônica integral de seus dados pessoais, observados os segredos comercial e industrial e nos termos de regulamentação da autoridade nacional, de acordo com o parágrafo $3^{\circ}$ do art. $9^{\circ}$. O documento deverá ser emitido em formato que permita a sua utilização posterior, inclusive em outras operações de tratamento. Nessa senda, os agentes controladores não poderão se valer dos tais sigilos empresariais para atuar de forma abusiva e desmedida (Cf.: MARQUES; BENJAMIN; MIRAGEM, 2010).

Constitui direito do titular a correção de dados incompletos, inexatos ou 


\section{TRATAMENTO DE DADOS PESSOAIS DOS CONSUMIDORES \\ : UMA ANÁLISE CRÍTICA ACERCA DOS DIREITOS \\ PREVISTOS NA LEI No 13.709/2018 E DA \\ RESPONSABILIZAÇÃO DOS AGENTES PELA AUTORIDADE \\ NACIONAL}

desatualizados $^{2}$, competindo ao controlador informar imediatamente aos agentes de tratamento com os quais tenha realizado uso compartilhado de informações, para que repitam idêntico procedimento. Outro importante direito corresponde à solicitação de revisão de decisões tomadas unicamente com base em tratamento informatizado de dados pessoais que afetem os interessados, inclusive de deliberações destinadas a definir o seu perfil pessoal, profissional, de consumo e de crédito ou os aspectos de sua personalidade. O controlador deverá fornecer, sempre que solicitadas, informações claras e adequadas a respeito dos critérios e dos procedimentos utilizados para a decisão automatizada, observados os segredos comercial e industrial. Em caso de não disponibilização dos esclarecimentos pugnados, sob a alegação de sigilo justificado, a autoridade nacional poderá realizar auditoria para verificar aspectos discriminatórios (BAUMAN, 2011; BAUDRILLARD, 2010).

O bloqueio ou a suspensão temporária de qualquer operação de tratamento encontra-se previsto como direito do titular, de acordo com o art. $5^{\circ}$, inciso XIII, da Lei. A exclusão definitiva do manejo de tais informações é outra importantíssima faculdade garantida para os cidadãos brasileiros, sendo modificado o teor do art. $7^{\circ}$, inciso $\mathrm{X}$, da Lei n. 12.965/14, que instituiu o Marco Civil da Internet, contemplando-a modo expresso (Cf. LESSIG, 2002). O art. 18, inciso V, previu ainda o direito de o titular requerer a portabilidade dos dados para outro fornecedor de serviço ou produto, mediante requisição expressa e observados os segredos comercial e industrial, de acordo com a regulamentação do órgão controlador (Cf: DONEDA, 2006).

\section{RESPONSABILIDADE DOS AGENTES DE TRATAMENTO DE DADOS E A ATUAÇÃO DA AUTORIDADE NACIONAL}

Inexistindo, por parte dos agentes que lidam com o tratamento de dados, a adoção de medidas eficazes e capazes de comprovar a observância e o cumprimento das normas de proteção e, inclusive, da eficácia de tais aparatos, devem ser

2 É o que dispõe o art. 18, inciso III, da Lei em análise.

Rev. de Direito, Globalização e Responsabilidade nas Relações de Consumo| e-ISSN: 2526-0030| Goiânia| v. 5 | n. 1 | p. 82-104| Jan/Jun. 2019 


\section{TRATAMENTO DE DADOS PESSOAIS DOS CONSUMIDORES \\ : UMA ANÁLISE CRÍTICA ACERCA DOS DIREITOS \\ PREVISTOS NA LEI No 13.709/2018 E DA \\ RESPONSABILIZAÇÃO DOS AGENTES PELA AUTORIDADE \\ NACIONAL}

responsabilizados. Compete-lhes evitar a ocorrência de danos em virtude da atividade e, outrossim, é fundamental que se utilizem de medidas, de natureza técnica e administrativa, que sejam eficientes. Visa-se a proteção contra acessos não autorizados e ainda de eventos acidentais ou ilícitos que possam causar destruição, perda, alteração, comunicação ou difusão.

A responsabilidade dos agentes que lidam com dados pessoais encontra-se consagrada na Lei $\mathrm{n}^{\circ} 13.709 / 2018$, nos arts. 42 a 45, que devem ser interpretados e aplicados em conformidade com o Código Civil Pátrio e com o microssistema consumerista, arregimentado pela Lei $\mathrm{n}^{0}$ 8.078/90. Estatui o aludido art. 45 que as hipóteses de violação do direito do titular, no âmbito das relações de consumo, permanecem sujeitas às regras de responsabilidade previstas na legislação pertinente. Nessa senda, o controlador, o operador e o encarregado que, em razão do exercício de atividade de tratamento de dados pessoais, violarem a legislação vigente, causando ao titular prejuízo patrimonial e/ou moral, serão obrigados a repará-lo, assim como serão responsabilizados diante do dano coletivo.

A despeito de a proposta legislativa em análise não mencionar, de modo expresso, que se trata de responsabilidade objetiva, dúvidas não podem pairar que será aplicada em sede desta atividade, visto que, se exercida de forma desmedida e desarrazoada, atinge direitos e liberdades fundamentais dos indivíduos (Cf.: SALEILLES, 1897; JOSSERAND, 1986; RIPERT, 1935; SILVA, 1960. AGUIAR DIAS, 1997; MIRANDA, 1958, p. 190). A solidariedade entre os controladores, operadores e encarregados encontra-se estampada nos parágrafos $1^{\circ}$ e $2^{\circ}$ do art. 42 , mas sendo acionado apenas um deles ou alguns, assegura o parágrafo $4^{\mathrm{o}}$ que aquele que reparar o dano ao titular tem direito de regresso contra os demais responsáveis, na medida de sua participação no evento danoso. O juiz, no processo civil, poderá inverter o ônus da prova a favor do titular dos dados quando, a seu juízo, for verossímil a alegação, houver hipossuficiência para fins de produção de prova ou esta resultar-lhe excessivamente onerosa, nos moldes do parágrafo $2^{\circ}$ do art. 42 . 


\section{TRATAMENTO DE DADOS PESSOAIS DOS CONSUMIDORES \\ : UMA ANÁLISE CRÍTICA ACERCA DOS DIREITOS \\ PREVISTOS NA LEI No 13.709/2018 E DA \\ RESPONSABILIZAÇÃO DOS AGENTES PELA AUTORIDADE NACIONAL}

\subsection{A AUTORIDADE NACIONAL: INSTITUIÇÃO E FUNÇÕES A SEREM EXERCIDAS}

Na pós-modernidade, a relevância da proteção de dados pertencentes às pessoas físicas é inquestionável e, com a edição da Lei $\mathrm{n}^{0}$ 13.709/18, foi vetada a instituição do Conselho Nacional de Proteção de Dados Pessoais e da Privacidade (CNPDP) e da Autoridade Nacional de Proteção de Dados (ANPD), que integrariam a administração pública federal indireta mediante regime autárquico especial e vinculação ao Ministério da Justiça. O Poder Executivo, no campo federal, teria que se inovar, através da instituição de tais entes, com o fito de poder materializar os ditames legais projetados, carecendo a estrutura atual de instrumentos que possam assumir a execução de tal tarefa, eis que já atribulados os existentes.

Nota-se que, na Medida Provisória $n^{0}$ 869/2018, que ensejou a Lei em exame, restou prevista a indicação de 4 (quatro) representantes de entidade do setor empresarial afeto à área de tratamento de dados pessoais. Não houve qualquer menção à possibilidade da presença de pessoas oriundas do âmbito das entidades que defendem os interesses e os direitos dos consumidores, aspecto que não se coaduna com a Constituição Federal de 1988 e com a Lei Federal $n^{0}$ 8.078/90, que estatuiu o microssistema em favor de tal coletividade, considerada composta por sujeitos vulneráveis. A ausência de sujeitos, que conheçam as agruras enfrentadas pelos destinatários finais de bens de consumo no atual mercado, estigmatizado por uma série de diversificadas práticas arbitrárias, fragilizaria, ainda mais, a proteção destes. $\mathrm{Na}$ condição de parte mais débil nas relações jurídicas entabuladas com os fornecedores, os consumidores, em frequentes situações, deparam-se com a utilização indevida dos seus dados pessoais.

A Autoridade Nacional de Proteção de Dados, como exposto alhures, terá a natureza de autarquia especial, caracterizando-se pela independência administrativa e ausência de subordinação hierárquica, possuindo os seus dirigentes mandato fixo, estabilidade e autonomia financeira. As atribuições da ANPD encontram-se 


\section{TRATAMENTO DE DADOS PESSOAIS DOS CONSUMIDORES \\ : UMA ANÁLISE CRÍTICA ACERCA DOS DIREITOS \\ PREVISTOS NA LEI No 13.709/2018 E DA \\ RESPONSABILIZAÇÃO DOS AGENTES PELA AUTORIDADE \\ NACIONAL}

prenunciadas pelo art. 57, incisos I a XVI, da Medida Provisória $\mathrm{n}^{\circ}$ 869/2018 e poderão ser agrupadas nas seguintes categorias: programadora e executiva; fiscalizatória e sancionadora; e informativa educacional. A primeira congrega as atividades de promoção de estudos sobre as práticas nacionais e internacionais de proteção de dados pessoais e privacidade e a consequente elaboração da Política Nacional pertinente. Competirá também à Autoridade Nacional ouvir os agentes de tratamento e a sociedade quanto às matérias de interesse relevante, para a obtenção de subsídios sobre a temática. A edição de regulamentos e procedimentos sobre o setor, assim como de relatórios de impacto quando o tratamento representar alto risco para a garantia dos princípios gerais de proteção de dados pessoais, constituem tarefas pertencentes à categoria em análise. $\mathrm{O}$ mesmo sucede com a elaboração e publicação de relatórios anuais de gestão, arrecadação e aplicação de receitas e despesas.

A atividade fiscalizatória e sancionadora da Autoridade Nacional poderá ser exercida mediante provocação do titular dos dados contra o controlador, através de petição, ou de ofício, quando constatado o tratamento realizado em descumprimento à legislação, mediante processo administrativo que assegure o contraditório, a ampla defesa e o direito de recurso. A ANPD deverá estimular a adoção de padrões para serviços e produtos que facilitem o exercício de controle dos titulares sobre seus dados pessoais, considerando as especificidades das atividades e o porte dos responsáveis. Poderá, a qualquer momento, solicitar a colaboração de entidades do Poder Público, para que concretizem operações de tratamento de dados pessoais e emissão de parecer técnico, bem como promovessem ações de cooperação com autoridades de proteção de dados pessoais de outros países, de natureza internacional ou transnacional. Será possível e viável a realização de auditorias, no âmbito da atividade de fiscalização. No campo educativo e informacional, constitui missão da Autoridade "disseminar o conhecimento das normas e das políticas públicas sobre proteção de dados pessoais e das medidas de segurança à população".

\subsection{AS SANÇÕES ADMINISTRATIVAS PASSÍVEIS DE APLICAÇÃO PELA}




\section{TRATAMENTO DE DADOS PESSOAIS DOS CONSUMIDORES \\ : UMA ANÁLISE CRÍTICA ACERCA DOS DIREITOS \\ PREVISTOS NA LEI No 13.709/2018 E DA \\ RESPONSABILIZAÇÃO DOS AGENTES PELA AUTORIDADE \\ NACIONAL}

\section{AUTORIDADE NACIONAL}

$\mathrm{O}$ art. 52 da Lei n. 13.709/18 estabelece que a autoridade nacional possui o poder de aplicar sanções de natureza pecuniária, objetiva e subjetiva. As primeiras referem-se às multas; as segundas encontram-se interligadas com os dados pessoais em tratamento; e as últimas vinculam-se ao exercício das atividades pelos agentes controladores. A posteriori, o art. 53 determina que aquela autoridade definirá, por meio de regulamento próprio, as penalidades administrativas aplicáveis às infrações cometidas. A aplicação de quaisquer sanções somente será cabível após procedimento administrativo que possibilite a oportunidade da ampla defesa, de forma gradativa, isolada ou cumulativa, de acordo com as peculiaridades do caso concreto. O parágrafo $2^{\circ}$ do citado art. 52 reza que o seu conteúdo "não substitui a aplicação de sanções administrativas, civis ou penais definidas em legislação específica" (DENARI; GRINOVER, 2011, bem como FINK, 2007).

De acordo com o parágrafo $1^{\circ}$ do art. 52, na incidência de qualquer penalidade, deverá ser observada a proporcionalidade entre a gravidade da falta e a intensidade da sanção, considerando-se, como parâmetros, critérios que dizem respeito à infração em si; à conduta do violador; e ao dano engendrado (Cf.: GELLHORN; LEVIN, 1997). Assim sendo, serão analisadas a natureza e a intensidade do ato transgressor, bem como os direitos pessoais afetados. Serão também averiguadas a vantagem auferida ou pretendida pelo infrator, se agiu com boa-fé, cooperou com a busca de soluções e adotou, de modo reiterado e demonstrado, mecanismos e procedimentos internos capazes de minimizar o dano, voltados ao tratamento seguro e adequado de dados. Verificar-se-á a utilização de boas práticas e governança; a pronta adoção de medidas corretivas, se a postura do infrator é reincidente; e a sua condição econômica. A extensão do dano causado para os titulares de dados é outro aspecto de grande relevância a ser considerado para a fixação da espécie de penalidade e, no caso de sanção pecuniária, o grau de seu montante.

A sanção pecuniária poderá ser de natureza simples ou diária, devendo o

Rev. de Direito, Globalização e Responsabilidade nas Relações de Consumo| e-ISSN: 2526-0030| Goiânia| v. 5 | n. 1 | p. 82-104| Jan/Jun. 2019 


\section{TRATAMENTO DE DADOS PESSOAIS DOS CONSUMIDORES \\ : UMA ANÁLISE CRÍTICA ACERCA DOS DIREITOS \\ PREVISTOS NA LEI No 13.709/2018 E DA \\ RESPONSABILIZAÇÃO DOS AGENTES PELA AUTORIDADE \\ NACIONAL}

regulamento estabelecer as circunstâncias e as condições para a escolha da modalidade. A primeira espécie atingirá o percentual máximo de até $2 \%$ (dois por cento) do faturamento da pessoa jurídica de direito privado, grupo ou conglomerado no Brasil, com base no seu último exercício, excluídos os tributos. Será restrita, no total, a R\$ 50.000.000,00 (cinquenta milhões de reais) por infração. Aplicando-se a penalidade sob o viés diário, observar-se-á também tal limite pecuniário, bem como a gravidade da falta e a extensão do dano ou prejuízo causado. Na intimação do agente acerca da multa diária, deverá constar, no mínimo, a descrição da obrigação imposta, o prazo estipulado pelo órgão para o seu cumprimento e o valor da penalidade, a ser aplicada pelo seu descumprimento ((Cf.: GELLHORN; LEVIN, 1997).

Percebe-se que não houve um avanço quanto à possibilidade de ser fixada sanção pecuniária mediante valores mais elevados, provavelmente devido às pressões exercidas pelos agentes que lidam com o tratamento de dados pessoais - situação que pode fragilizar a proteção dos consumidores (DENARI, 2011, p. 786). O art. 53, no seu caput, inclusive, dispõe que as metodologias que orientarão o cálculo do valor-base das multas deverão ser submetidas a consultas públicas por parte da autoridade nacional. Exige o parágrafo $1^{\circ}$ que tais sistematizações sejam, previamente, publicadas, para ciência dos agentes de tratamento, devendo apresentar objetivamente as formas e dosimetrias para o montante, que deverão conter fundamentação detalhada de todos os seus elementos, demonstrando a observância dos critérios legais previstos.

As sanções objetivas podem ser advertência, com indicação de prazo para adoção de medidas corretivas; bloqueio dos dados pessoais a que se refere a infração até a regularização da atividade de tratamento pelo controlador; eliminação de tais informações; e publicização do ato transgressor, após devidamente apurada e confirmada a sua ocorrência. Já as penalidades subjetivas podem ensejar a suspensão, parcial ou total, do funcionamento do banco de dados, a que se refere a infração, pelo tempo máximo de 06 (seis) meses, prorrogável por igual período, até a regularização da atividade. Poderá ser decretada a descontinuação temporária do exercício da atividade 


\section{TRATAMENTO DE DADOS PESSOAIS DOS CONSUMIDORES \\ : UMA ANÁLISE CRÍTICA ACERCA DOS DIREITOS \\ PREVISTOS NA LEI No 13.709/2018 E DA \\ RESPONSABILIZAÇÃO DOS AGENTES PELA AUTORIDADE \\ NACIONAL}

de tratamento dos dados pessoais no decorrer de, no máximo, 06 (seis) meses, ampliável por idêntico prazo. Será também aplicável a proibição, parcial ou total, da realização de tarefas relacionadas ao tratamento de dados.

\section{CONCLUSÃO}

A Lei Federal $n^{0}$ 13.709/18 decorre do objetivo do Brasil de acompanhar os meandros percorridos por vários outros países no sentido de proteger os dados pessoais dos indivíduos quando manejados em atividades de natureza econômica. Tenciona-se fomentar o respeito aos relevantes direitos de privacidade, intimidade, honra e imagem, primando-se pela dignidade dos sujeitos, em cotejo com o desenvolvimento econômico, tecnológico e a inovação, preservando-se também a liberdade de expressão, informação, comunicação e opinião. Entretanto, não obstante albergue o diploma legal inovações na seara jurídica, nota-se a existência de dois conjuntos de fatores fundamentais que podem fragilizar os direitos dos consumidores, quais sejam: a existência de dispositivos normativos que suscitam uma atenção especial quanto à interpretação e à aplicação; e a necessidade de efetiva atuação da Autoridade Nacional de Proteção de Dados (ANPD) e do Conselho Nacional de Proteção de Dados e Privacidade.

No que concerne ao primeiro aspecto, denotam bastante preocupação as normas que versam sobre o consentimento dos titulares; o direito à informação destes; e a responsabilidade dos agentes controladores. Quanto às primeiras, deve-se atentar para as situações de dispensa do prévio aval do titular, bem como à forma por meio da qual o interessado aquiesce com o tratamento dos seus dados pessoais. $\mathrm{O}$ segundo pode ser obstaculizado pelos intitulados segredos industrial e comercial, que são mencionados, no texto legal, em várias disposições. A problemática atinente à responsabilização é outro aspecto que requer uma cuidadosa análise em consonância com as determinações emanadas do Código de Proteção e Defesa do Consumidor.

O veto presidencial aos dispositivos que arregimentavam a instituição do CNPDP e da ANPD e a sua posterior previsão por meio de Medida Provisória denotam as dificuldades para a efetividade de vários dispositivos presentes na Lei Federal $\mathrm{n}^{\mathrm{o}}$ 13.709/18 no que concerne à proteção dos interesses e direitos dos consumidores. $\mathrm{O}$ Sistema Nacional de Defesa dos Consumidores (SNDC) possui a missão de defendê-los

Rev. de Direito, Globalização e Responsabilidade nas Relações de Consumo| e-ISSN: 2526-0030| Goiânia| v. 5 | n. 1 | p. 82-104| Jan/Jun. 2019 


\section{TRATAMENTO DE DADOS PESSOAIS DOS CONSUMIDORES : UMA ANÁLISE CRÍTICA ACERCA DOS DIREITOS \\ PREVISTOS NA LEI No 13.709/2018 E DA \\ RESPONSABILIZAÇÃO DOS AGENTES PELA AUTORIDADE NACIONAL}

em face das práticas deletérias observadas no setor mercadológico e terá que se planejar, para que possa também acompanhar e fiscalizar o tratamento de dados pessoais realizado pelos agentes controladores. Nessa senda, conquanto os entes e órgãos, que componham tal estrutura, já se encontrem assoberbados com uma diversidade de atribuições, fundamental será uma atuação coesa, integrada e coordenada para prevenir e combater o manejo arbitrário de informações atinentes aos destinatários finais de bens. REFERÊNCIAS

ADER-DUCOS, Robert; AUBY, Jean Marie. Droit de l'information. Paris: Dalloz, 1982.

AGUIAR DIAS, José de. Da responsabilidade civil. 10. ed. Rio de Janeiro: Forense, 1997.

ALMEIDA, Carlos Ferreira de. Os direitos dos consumidores. Coimbra: Almedina, 1982.

ALPA, Guido; BESSONE, Mario. Il diritto dei consumatori. Roma-Bari: Gius. Latreza\&Figli, 2001.

BARBER, Benjamin R. Consumido. Como o mercado corrompe crianças, infantiliza adultos e engole cidadãos. Trad. Bruno Casotti. Rio de Janeiro/São Paulo: Record, 2009.

BARRON, John; STATEN, Michael. The value of comprehensive credit reports: lessons from the U.S. Experience. In: MILLER, Margaret J. (ed) Credit reporting systems and the international economy. Cambridge: MIT Press, 2003, p. 306-307.

BAUDRILlARD, Jean. A Sociedade de Consumo. Trad. Artur Morão. Lisboa: Edições 70, LDA, 2010.

BAUMAN, Zygmunt. A Ética é Possível num Mundo de Consumidores? Trad. Alexandre Werneck. São Paulo: Zahar, 2011.

BEAUCHARD, Jean. Droit de la distribution et de la consommation. Paris: PUF, 1996.

BECKER, Howard S. Métodos de pesquisa em ciências sociais. São Paulo: Hucitec, 1999.

BENNETT, Colin. Regulating privacy, Data protection and public policy in Europe and the United States. Ithaca: Cornell University Press, 1992.

BOURGOIGNIE, Thierry. O conceito de abusividade em relação aos consumidores e a necessidade de seu controle através de uma cláusula geral. Revista de Direito do Consumidor, São Paulo, Revista dos Tribunais, número 06, p. 07, 1993.

BRIN, David. The transparent society. Massachusetts: Addison-Wesley, 1998.

CALAIS-AULOY, Jean; STEINMETZ, Frank Steinmetz. Droit de la consommation. 7. ed. Paris: Dalloz, 2006.

CANCLINI, N. G. Consumidores e cidadãos: conflitos multiculturais da globalização. Rio de Janeiro: UFRJ, 2006.

COMPARATO, Fábio Konder. A proteção do consumidor: importante capítulo do direito econômico. Revista da Consultoria Geral do Estado do RS, n. 6, Porto Alegre,

Rev. de Direito, Globalização e Responsabilidade nas Relações de Consumo| e-ISSN: 2526-0030| Goiânia| v. 5 | n. 1 | p. 82-104| Jan/Jun. 2019 


\section{TRATAMENTO DE DADOS PESSOAIS DOS CONSUMIDORES : UMA ANÁLISE CRÍTICA ACERCA DOS DIREITOS \\ PREVISTOS NA LEI No 13.709/2018 E DA \\ RESPONSABILIZAÇÃO DOS AGENTES PELA AUTORIDADE \\ NACIONAL}

1976, p. 85-105.

CANOTILHO, José Joaquim Gomes. Direito Constitucional e Teoria da Constituição. 5 ed. Coimbra: Almedina, 2002.

; MOREIRA, Vital. Fundamentos da Constituição. Coimbra: Coimbra Editora,

CASTELLS, Manuel. A sociedade em rede. A era da informação, economia, sociedade e cultura. V. 1. São Paulo: Paz e Terra, 2008, p. 64-65.

CASTRO, Catarina Sarmento e. Direito da Informática, privacidade e dados pessoais. Coimbra: Edições Almedina, 2005.

CATALA, Pierre. Ebauche d'une théorie juridique de l'information. Informatica e Diritto, ano IX, jan-apr. 1983.

DE CUPIS, Adriano. I diritti della personalità, Milano, Giuffrè, 1982.

. Il Danno. Milão: Giuffrè, 1954.

DENARI, Zelmo; GRINOVER, Ada Pellegrini; BENJAMIN, Antônio Herman de Vasconcelos. et al. Código Brasileiro de Defesa do Consumidor. 10. ed. rev. atual. e reform. Rio de Janeiro: Forense, 2011, volume I.

DE LA CUEVA, Pablo Lucas Murillo. Informática y protección de datos personales. Madri: Centro de Estudios Constitucionales, 1993.

DONEDA, Danilo. Da privacidade à proteção de dados pessoais. Rio de Janeiro: Renovar: 2006.

FERRIER, Didier. La protection des consommateurs. Paris: Dalloz, 1996.

FINK, Daniel Roberto; BENJAMIN, Antônio Herman et alii. Código Brasileiro de Defesa do Consumidor comentado pelos autores do anteprojeto. 9. ed. rev. amp. atual e ampl. São Paulo/Rio de Janeiro: Forense Universitária, 2007.

FROSINI, Vittorio. Towards information law. In: Informatica e diritto. vol. V, n. 2, 1995, p. 7-16.

GELLHORN, Ernest; LEVIN, Ronald. Administrative Law and Process. 4. ed. St. Paul: West Publishing, 1997.

GHERSI, Carlos Alberto. A. Tutela del consumidor, v. 2. Argentina: Ediciones Jurídicas Cuyo, 2004.

GHESTIN, Jacques. L'utile et le juste dans le contrat. Recueil Dalloz, Paris, Dalloz, $1^{\circ}$ caderno, Chronique, p. 1-10, 1962.

GONÇALVES, Maria Eduarda. Direito da Informação: novos direitos e formas de regulação na sociedade da informação. Coimbra: Almedina, 2003.

HERRERA, Enrique. Práctica metodológica de la investigación jurídica. Buenos Aires: Astrea, 1998.

JOSSERAND, Louis. Derecho civil. Evolução da responsabilidade civil. Trad. Raul Lima. Rio de Janeiro: Revista Forense, 1986.

LESSIG, Lawrence. Code and other laws of cyberspace. Basic Books: New York, 1999. The future of ideas. Vintage: New York, 2002.

LÉVY, Pierre. Qu'est-ce que le virtuel? Paris: La Découverte, 1998.

MARQUES, Claudia Lima; BENJAMIN, Antônio Herman V.; MIRAGEM, Bruno.

Rev. de Direito, Globalização e Responsabilidade nas Relações de Consumo| e-ISSN: 2526-0030| Goiânia| v. 5 | n. 1 | p. 82-104| Jan/Jun. 2019 


\section{TRATAMENTO DE DADOS PESSOAIS DOS CONSUMIDORES : UMA ANÁLISE CRÍTICA ACERCA DOS DIREITOS \\ PREVISTOS NA LEI No 13.709/2018 E DA \\ RESPONSABILIZAÇÃO DOS AGENTES PELA AUTORIDADE NACIONAL}

Comentários ao Código de Defesa do Consumidor. 3. ed. rev. ampl. e atual. São Paulo: Revista dos Tribunais, 2010.

; MIRAGEM, Bruno. O Novo Direito Privado e a Proteção dos Vulneráveis. São Paulo: Revista dos Tribunais, 2012.

MAYER-SCHÖNBERGER,Viktor. General development of data protection in Europe. In: AGRE, Phillip; ROTENBERG, Marc (orgs.). Technology and privacy: The new landscape. Cambridge: MIT Press, 1997, p. 219-242.

Delete. The Virtue of Forgetting in the Digital Age. Princeton: Princeton University Press, 2009.

MESSINETTI, David. Circolazione dei dati personali e dispositivi de regolazione dei poteri individuali. In: Rivista Critica del Diritto Privato, 1998, p. 339-407.

MIRAGEM, Bruno; MARQUES, Claudia Lima. O Novo Direito Privado e a Proteção dos Vulneráveis. São Paulo: Revista dos Tribunais, 2012.

MIRANDA, Pontes de. Tratado de Direito Privado. Direito das Obrigações. Tomo XXII. Rio de Janeiro: Borsoi, 1958, parágrafo 2718, p. 190.

OSSOLA, Federico; VALLESPINOS, Carlos Gustavo. La obligación de informar. Córdoba: Advocatus, 2001.

PARDOLESI, Roberto. Dalla riservatezza alla protezione dei dati personali: una storia di evoluzione e discontinuità. In: Diritto alla riservatezza e circolazione dei dati personali. Milano: Giuffrè, 2003, p. 1- 57.

PÉREZ-LUÑO, Antonio-Enrique. Derechos humanos, Estado de Derecho y Constitución. 9. ed. Madri: Editorial Tecnos, 2005.

PINTO, Carlos Alberto da Mota. Teoria geral do direito civil. 3. ed. Coimbra: Ed. Coimbra, 1996.

POULLET, Yves. Data Protection Legislation: What's at Stake for our Society and our Democracy? In: Computer Law \& Security Review, Vol. 25, Is. 3, 2009, pp. 211-226.

RIPERT, Georges. La règle morale dans les obligations civiles. Paris: LGDJ, 1935.

RODOTÀ, Stefano. A vida na sociedade da vigilância. A privacidade hoje. Rio de Janeiro: Renovar, 2008.

RULE, James; HUNTER, Lawrence. Towards a property right in personal data. In: BENNETT, Colin. Visions of privacy: Policy choices for the digital age. Toronto: University of Toronto Press, 1999.

SALEILLES, Raymond. Les accidents de travail et la responsbilité civile. In: Essai d'une théorie objective de la responsabilité délictuelle, 1897.

WACKS, Raymond. Personal information. Oxford: Clarendon Press, 1989.

WITKER, Jorge. Como elaborar una tesis en derecho: pautas metodológicas y técnicas para el estudiante o investigador del derecho. Madrid: Civitas, 1985. 